\title{
SIN GARANTÍAS NO HAY DERECHOS. SIN DERECHOS NO HAY CONSTITUCIÓN. APUNTES SOBRE LA PROTECCIÓN JURISDICCIONAL DE LOS DERECHOS EN ECUADOR
}

MARCO APARICIO WILHELMI 


\section{SUMARIO}

1. INTRODUCCIÓN. 2. LAS GARANTÍAS JURISDICCIONALES DE LOS DERECHOS CONSTITUCIONALES: CUESTIONES GENERALES. 2.1. Principios generales del procedimiento. 2.2. Reparación integral. 2.3. Apelación y selección de casos por la Corte Constitucional. 3. LAS ACCIONES DE PROTECCIÓN DE LOS DERECHOS CONSTITUCIONALES: APORTACIONES MÁS RELEVANTES DE LA LOGJCC. 3.1. Medidas Cautelares. 3.2. Acción de Protección. 3.3. Acción de hábeas corpus. 3.4. Acción por incumplimiento. 3.5. Acciones extraordinarias de protección. 3.6. Acción extraordinaria de protección contra decisiones de la justicia indígena. 


\title{
SIN GARANTÍAS NO HAY DERECHOS. SIN DERECHOS NO HAY CONSTITUCIÓN. APUNTES SOBRE LA PROTECCIÓN JURISDICCIONAL DE LOS DERECHOS EN ECUADOR
}

\begin{abstract}
POR
MARCO APARICIO WILHELMI*

La garantía de los derechos de la mujer y de la ciudadana necesita de un bien mayor; esta garantía debe instaurarse en beneficio de todas y no para la utilidad particular de aquéllas a quien se confíe

(Artículo XII de la Declaración de Derechos de la Mujer y de la Ciudadana, Olympe de Gouges, 1791)

La garantía social consiste en la acción de todos para asegurar a cada uno el goce y la conservación de sus derechos (Artículo 23, primer inciso, de la Declaración de Derechos del Hombre y del Ciudadano de 1793)

Hay opresión contra el cuerpo social cuando uno sólo de sus miembros es oprimido (Artículo 34, primer inciso, de la Declaración de Derechos del Hombre y del Ciudadano de 1793)
\end{abstract}

\section{INTRODUCCIÓN}

El presente texto va a centrar su análisis en las garantías jurisdiccionales de los derechos recogidos por la vigente Constitución ecuatoriana, de acuerdo con el

\footnotetext{
*Profesor de Derecho constitucional en la Universitat de Girona. marco.aparicio@udg.edu
} 
desarrollo que de las mismas ha realizado la Ley Orgánica de Garantías Jurisdiccionales y Control Constitucional, de 21 de septiembre de 2009 (en adelante, LOGJCC).

Para cubrir tal objetivo, puede resultar útil una breve introducción sobre el marco constitucional en que dichas garantías encuentran asiento. La Constitución de 2008 define al Estado ecuatoriano como «Estado constitucional de derechos» (art. 1) $)^{1}$. Con esta categorización se pretende anunciar la superación de la tradicional alusión al «Estado de derecho», anclada en la tradición liberal de sujeción de los poderes públicos al ordenamiento jurídico. Esta sujeción se asume pero completándola con una especial mención de la vinculación no al Derecho sin más, sino a los derechos. Con ello se sitúa a sus titulares, a los sujetos, ya sean individuales o colectivos, como auténtica razón de ser del Estado y del ordenamiento jurídico, como pieza básica, activa, y no como mero objeto de regulación. En definitiva, con nitidez se diseña el carácter instrumental de la organización política y de los mecanismos jurídicos para la protección de las necesidades o intereses de las personas, de los grupos y de la naturaleza; se trata de las condiciones para la realización del «buen vivir» o sumak kawsay que inunda el texto constitucional.

Desde tales parámetros, la Constitución de 2008 ha sido calificada como paradigma del nuevo constitucionalismo garantista en buena medida porque más allá de la amplitud del listado de derechos consagrado, trata de reforzar con obstinada determinación su efectividad mediante garantías de distinto tipo, tanto institucionales como no institucionales (o sociales). Así es, el texto constitucional establece criterios llamados a evitar que los derechos enunciados se queden en meras aspiraciones, empeños difuminados por las dinámicas de dominación económica, social y cultural, y por un ineficiente funcionamiento de las instituciones.

Como garantías institucionales, la nueva Constitución incorpora garantías primarias, es decir, establece mandatos y habilita a los poderes públicos, tanto Legislativo como Ejecutivo, para la puesta en marcha de las políticas que deben generar las condiciones jurídicas y materiales de realización de los derechos ${ }^{2}$. Por si éstas fallaran, se prevé un variado y bien armado régimen de garantías secun-

${ }^{1}$ Un marco introductorio general puede hallarse en Ramiro Ávila Santamaría, «El constitucionalismo ecuatoriano. Breve caracterización de la Constitución de 2008», publicado en la Biblioteca Virtual del Instituto de Investigaciones Jurídicas de la UNAM, http://www.bibliojuridica.org/libros/6/2701/34.pdf

2 A tales garantías, se dedican íntegramente dos títulos de la Constitución: el sexto («régimen de desarrollo») y séptimo («régimen del buen vivir»), que comprenden un total de ciento cuarenta y ocho artículos. 
darias o jurisdiccionales, tanto en el ámbito de la Función Judicial como mediante distintas vías de acceso a la Corte Constitucional. Y, por último, el texto incorpora, explícitamente, mecanismos sociales de exigencia y control, por medio de la Función de Transparencia y Control Social (capítulo quinto del título IV), además de las distintas formas de participación (capítulo primero del título IV) y de los derechos que en sí mismos implican formas de exigencia y de control ciudadano (derechos de reunión y manifestación, de asociación, de expresión e información, etc.).

Junto con tales mecanismos, la Constitución opta por agregar una serie de principios de aplicación contemplados en el capítulo primero del título II. Se trata de mandatos que necesariamente deberán ser observados por las instituciones cuando de la efectividad de los derechos se trate, y se enmarcan en el carácter inalienable, irrenunciable, indivisible, interdependiente y la igual jerarquía de todos los derechos (artículo 11.6). Merece la pena destacar, a modo meramente enunciativo $^{3}$, los siguientes principios generales de aplicación: principio de exigibilidad, tanto individual como colectiva; de igualdad; de directa e inmediata aplicabilidad; de plena justiciabilidad; de responsabilidad del Estado tanto por las acciones como por las omisiones que provoquen vulneraciones de derechos; $y$ de no regresividad, que impide cualquier acción u omisión que, de manera injustificada, menoscabe el contenido de derechos ya reconocidos.

El catálogo de principios aplicativos y de garantías previstas se refieren, por igual, a un amplio listado de derechos constitucionalmente consagrados: del buen vivir (capítulo segundo); derechos de las personas y grupos de atención prioritaria (capítulo tercero); derechos de las comunidades, pueblos y nacionalidades (capítulo cuarto); derechos de participación (capítulo quinto); derechos de libertad (capítulo sexto); derechos de la naturaleza (capítulo séptimo); y derechos de protección (capítulo octavo).

Roberto Gargarella, entre otros, ha advertido de los riesgos de una apuesta de derechos «inflacionista» dado que, considera el profesor argentino, «será difícil, e incluso imposible, satisfacer muchos de los que se incorporaron en las nuevas Constituciones». Ahora bien, el mismo autor se encarga de señalar que tales riesgos no deben conducirnos «a descalificar de manera automática la operación de expandir el apartado de los derechos» ya que ejemplos «de Constituciones austeras como la norteamericana o, en Latinoamérica, la de Chile vienen de la

${ }^{3}$ Un mayor desarrollo de esta cuestiones puede hallarse en M. Aparicio Wilhelmi, «Derechos: enunciación y principios de aplicación», en R. Ávila, A. Grijalva, R. Martínez, Desafíos constitucionales. La Constitución ecuatoriana del 2008 en perspectiva, Ministerio de Justicia y Derechos Humanos y Tribunal Constitucional, Quito, 2008. 
mano de una práctica — judicial, en particular - muy hostil frente a los derechos sociales, culturales o económicos, en general. Ocurre que cuando los jueces no encuentran un respaldo escrito para esos derechos nuevos — es decir, cuando la Constitución no menciona el derecho a la salud o los nuevos derechos de los indígenas-, tienden a actuar como si esos derechos no existieran en absoluto» ${ }^{4}$.

Es bien sabido, sin duda, que la incorporación de derechos que atienden las reivindicaciones sociales y culturales de los colectivos más vulnerables de la sociedad no asegura por si sola su efectividad. Detrás de los derechos existen expectativas, necesidades e intereses cuya realización necesariamente implica contradicciones. Un derecho, como pretensión tendencialmente generalizable de sujetos que se hallan en condiciones equiparables, es lo opuesto a un privilegio, pretensión excluyente, desigualitaria. La realización de los primeros forzosamente deberá empujar al destierro de los segundos.

No es este el lugar para adentrarnos en la variedad de implicaciones que la efectividad de los derechos contrae pero merece la pena, en este apartado introductorio a un análisis sobre mecanismos jurisdiccionales de protección, señalar la necesidad de huir de un legicentrismo excesivo. Es necesario desconfiar prudentemente del poder de la letra de la ley en la determinación del comportamiento de los distintos sujetos y poderes, públicos y privados, que conforman nuestras sociedades. Por garantistas y comprometidos que puedan llegar a ser sus propósitos, un Derecho desconectado de las circunstancias sociales en las que se inserta y de las condiciones que posibilitan que sea apropiado, reivindicado y actuado por los sujetos destinatarios, se acaba convirtiendo a menudo en un elemento de contención, de freno a los cambios sociales 5 .

Se trata de la doble cara del Derecho y, en especial, de su carácter complejo y hasta cierto punto contradictorio: por un lado, puede ofrecer avances, mejoras de las condiciones para la transformación social a partir de un contexto jurídico-político en el que se incorporan nuevos derechos y nuevos actores anteriormente marginados; por otro lado, el texto jurídico formaliza consensos pero también exclusiones, abre el espacio político a unos mientras lo cierra para otros. Avance y freno; apertura y cierre.

Planteado el marco general de la reflexión, podemos ya adentrarnos en el análisis del desarrollo que realiza la LOGJCC del conjunto de mecanismos juris-

${ }^{4}$ R. Gargarella, «Las nuevas Constituciones. Promesas e interrogantes en América Latina» en la revista electrónica Todavía: http://www.revistatodavia.com.ar/todavia21/21.politicanota.html

5 Aunque desde una perspectiva quizás excesivamente desconfiada hacia la capacidad prescriptiva del Derecho, de ellos nos advirtió hace ya bastante tiempo Ferdinand Lassalle en su conocida obra: ¿Qué es una Constitución?, Ariel, Barcelona, 1984. 
diccionales propuestos por la Constitución ecuatoriana para la garantía de los derechos.

\section{LAS GARANTÍAS JURISDICCIONALES DE LOS DERECHOS CONSTITUCIONALES: CUESTIONES GENERALES}

\subsection{Principios generales del procedimiento}

Como expresión avanzada del nuevo constitucionalismo latinoamericano, la Constitución ecuatoriana de 2008 incorpora las bases de lo que debe suponer una transformación de la justicia con el objeto de hacerla plural, eficaz, próxima, accesible y comprensible para el conjunto de la ciudadanía. En este sentido, se amplían las vías de acceso a los tribunales, en especial para la protección de los derechos, y se establecen como principios generales del proceso la oralidad, la gratuidad, la inmediación, la celeridad y economía procesal, y el anti-formalismo (artículos 168 y 169) ${ }^{6}$.

Respecto de las vías específicas para la protección de los derechos, la Constitución menciona en su artículo 436.6 que la Corte Constitucional tendrá competencia para «expedir sentencias que constituyan jurisprudencia vinculante respecto de las acciones de protección, cumplimiento, hábeas corpus, hábeas data, acceso a la información pública y demás procesos constitucionales, así como los casos seleccionados por la Corte para su revisión». Además de tales mecanismos de garantía, el artículo 437 recoge la acción extraordinaria de protección contra sentencias firmes, autos definitivos y resoluciones con fuerza de sentencia que supongan una vulneración, por acción u omisión, del debido proceso u otros derechos reconocidos en la Constitución. Por su parte, el artículo 439 concreta el principio de accesibilidad a la jurisdicción constitucional al establecer que «las acciones constitucionales podrán ser presentadas por cualquier ciudadana o ciudadano individual o colectivamente».

${ }^{6}$ Como marco general de comprensión pueden verse los siguientes textos: Carolina Silva Portero, «Las garantías de los derechos ¿invención o reconstrucción?», en Ramiro Ávila Santamaría, Neoconstitucionalismo y sociedad, Ministerio de Justicia y Derechos Humanos, Quito, 2008, pp. 51-84. Y Ramiro Ávila Santamaría, «Las garantías: herramientas imprescindibles para el cumplimiento de los derechos. Avances conceptuales en la Constitución de 2008», en Ramiro Ávila Santamaría, Rubén Martínez Dalmau, y Agustín Grijalba Jiménez, Desafíos constitucionales. La Constitución ecuatoriana de 2008 en perspectiva, Ministerio de Justicia y Derechos Humanos, Quito, 2008, pp. 89-110. 
Con tales presupuestos, la LOGJCC ha encarado el reto, como indica en sus considerandos, de articular «recursos sencillos y rápidos ante los jueces o tribunales competentes que les permitan amparar a los seres humanos y a la naturaleza frente a actos u omisiones que amenacen o violen sus derechos, y adoptar las medidas pertinentes para asegurar la reparación integral».

Debemos adentrarnos en la mencionada ley para poder formarnos un juicio más fundamentado. En primer término, debe destacarse como aportación relevante la incorporación de un listado de principios propios de la justicia constitucional (artículo 2) y uno de métodos y reglas de interpretación constitucional (artículo 3). Esta opción, que no resulta habitual en otras legislaciones sobre garantías constitucionales, debe valorarse positivamente. En primer lugar, porque una justicia que se quiera accesible debe partir por clarificar las pautas que el órgano juzgador va a utilizar en sus decisiones. En segundo lugar, porque los principios recogidos vienen a trasladar a una lógica constitucional, de derecho público, unos criterios habitualmente recogidos en los códigos civiles y, por tanto, propios del ámbito iusprivatista. Especialmente cabe destacar que se recojan los principios de proporcionalidad y ponderación, principios esenciales en la aplicación y efectividad de los derechos, perfilados en buena medida gracias a la jurisprudencia de los tribunales internacionales de protección de los derechos humanos, como la Corte Interamericana de derechos humanos o, en el ámbito regional europeo, el Tribunal europeo de los derechos humanos.

Además de los principios interpretativos, la LOGJCC incorpora los principios procesales que regirán la actividad de la justicia constitucional (artículo 4). $\mathrm{Al}$ margen de los previstos en el propio texto constitucional, merece la pena destacar los principios de impulso de oficio, dirección del proceso por parte del órgano juzgador, doble instancia, formalidad condicionada al logro de los fines del proceso y posibilidad de saneamiento por la parte en cuyo favor se establezcan las formalidades, motivación adecuada y comprensión efectiva, esto es, la necesidad de que el órgano judicial redacte las resoluciones «de forma clara, concreta, inteligible, asequible y sintética».

Esa impronta de la subordinación de las formas a la garantía material de los derechos se deja ver, de nuevo, en el conjunto de normas comunes a todas las acciones de garantía de los derechos constitucionales reguladas por la Ley (artículo 8). En ellas se establece la oralidad para todas las fases e instancias, limitando el escrito a determinadas actuaciones (demanda, su calificación, su contestación, y las sentencias o autos que aprueben el acto reparatorio). En la misma línea, se determina que las notificaciones deberán realizarse por los medios más eficaces y que no se requerirá la asistencia de una abogada o abogado ni para 
interponer la acción ni para apelar ${ }^{7}$. Además, reforzando el principio de accesibilidad, se habilitan todos los días y horas para las actuaciones procesales; igualmente, se garantiza la competencia de la juez o juez más cercano (artículo 7).

Merece la pena subrayar la trascendencia de la exclusión del carácter necesario de la asistencia letrada. Más allá de agilizar y facilitar el acceso inmediato a la justicia, la importancia radica en el efecto transformador que puede llegar a tener en las prácticas procesales y en la comprensión y papel mismo del Derecho y de los derechos. El acceso directo, sin mediaciones de expertos, de las personas afectadas a los mecanismos de defensa de sus propios derechos puede impulsar un cambio radical en las formas de impartir justicia. El hecho de que en las audiencias el sujeto protagonista no sea el abogado sino la persona afectada, junto con la circunstancia de que ésta será en muchas ocasiones la que actúe directamente en los procesos, debe, necesariamente, empujar a una transformación de las formas, del lenguaje, y, con ello, de la misma estructura de razonamiento.

No obstante, deben también advertirse el peligro de asimetría que puede generarse entre quienes defiendan su causa directamente y quienes lo hagan por medio de abogados. Se trata de un proceso de transformación no exento de interrogantes. A medida que la mayor cercanía de la ciudadanía a los mecanismos jurídicos de protección vaya tomando forma, crecerá el interés social por su conocimiento y, con él, debe esperarse, aumentará la confianza en el uso directo de tales mecanismos.

Debe señalarse que la LOGJCC parece ser consciente de la necesidad de allanar dicho camino, y así lo hace no sólo con el conjunto de principios referidos sino también con una serie de previsiones que buscan facilitar la comprensión de los aspectos, requisitos y formalidades básicas que deben estar presentes en los procesos (capítulo II del Título I de la Ley). En especial, se demuestra dicho empeño al especificar los elementos que deberá contener toda demanda (artículo 10) y en el detalle explicativo, además de prescriptivo, de los momentos y aspectos que deberán concurrir en las audiencias públicas (artículo 14) y en la presentación y valoración de las pruebas (artículo 16).

Otro aspecto que merece la pena comentar es la ampliación de los sujetos intervinientes en las acciones de protección de los derechos. Además de establecer

${ }^{7}$ Podría llegar a interpretarse que el precepto que recoge esta previsión pareciera dejar la puerta abierta a que en ocasiones se llegue a exigir la asistencia de abogada o abogado, ya que añade que «de ser necesario o cuando la persona lo solicite» se designará un defensor público. Ahora bien, de acuerdo con el sentido general de la norma, resulta más ajustado entender que esa alusión al carácter necesario de la asistencia técnica se refiere a los casos en que las circunstancias del caso o del sujeto así lo aconsejen, pero que quedará siempre a voluntad de la persona afectada. 
una legitimación activa abierta al Defensor del pueblo y a «cualquier persona, comunidad, pueblo, nacionalidad o colectivo» afectada por la vulneración de algún derecho constitucional (artículo 9), se prevé la posibilidad de que cualquier persona o grupo que tenga interés pueda presentar un escrito de amicus curiae (artículo 12), mecanismo que en el ámbito de la justicia internacional de los derechos humanos ha demostrado su utilidad al ampliar no sólo las posibilidades de defensa de los derechos vulnerados, sino por generar la implicación de organizaciones sociales, desencadenante de la expansión del debate y de la apropiación social de la cultura de los derechos.

\subsection{Reparación integral}

Debe hacerse una mención especial a la regulación del alcance de la reparación en caso de vulneraciones de derechos. El artículo 18 recoge de manera detallada los modos en que puede afrontarse la reparación, que deberá ser integral, de los daños materiales e inmateriales causados. De nuevo se deja notar la impronta de los desarrollos más recientes del sistema internacional de protección de los derechos humanos. Según la Subcomisión de Prevención de Discriminaciones y Protección a las Minorías de Naciones Unidas, «los Estados tienen el deber de adoptar, cuando la situación lo requiera, medidas especiales a fin de permitir el otorgamiento de una reparación rápida y plenamente eficaz. La reparación deberá lograr soluciones de justicia, eliminando o reparando las consecuencias del perjuicio padecido, así como evitando que se cometan nuevas violaciones a través de la prevención y la disuasión. La reparación deberá ser proporcionada a la gravedad de las violaciones y del perjuicio sufrido, y comprenderá la restitución, compensación, rehabilitación, satisfacción y garantías de no repetición» ${ }^{8}$.

Dado que el propósito de que se recupere la situación anterior a la vulneración del derecho se presenta como un imposible material, en realidad, afirma Graciela Guilis, «será en la construcción de la definición simbólica de la sanción, que deberá darse tanto en la singularidad del afectado directo como en lo colectivo, donde se nos impone la necesidad de revisar qué lugar y qué estatuto se le otorga a la construcción del concepto de reparación». En esta línea, señala la mis-

${ }^{8}$ Uno de los documentos centrales en materia de reparación en el ámbito de Naciones Unidas son los «Principios y directrices sobre el derecho de las víctimas de violaciones graves a los derechos humanos y al Derecho humanitario, a obtener reparación»: E/CN.4/Sub.2/1996/17 (24 de mayo de 1996).

http://www.unhchr.ch/Huridocda/Huridoca.nsf/0/9980726ac39e5828802566aa003ac4b2?Op $\underline{\text { endocument }}$ 
ma autora, deberíamos trazar una distinción fundamental entre reparación y acto reparatorio: «la justicia produce, propicia, obliga a generar un acto reparatorio por parte del culpable de los delitos. Pero que estos actos se traduzcan en un efecto de reparación, ya no depende directamente de la justicia, sino de la dinámica psíquica de la víctima. La reparación — como operación psíquica - no es un acto que produce el culpable respondiendo al requerimiento de la justicia, sino que dependerá de la forma de metabolización que la víctima pueda realizar respecto de ese acto reparatorio» ${ }^{9}$.

Por ello debe valorarse positivamente que la LOGJCC desarrolle la exigencia, ya recogida por la Constitución (artículos 78, 86 y 397), de reparación integral pues con ello se supera la lógica del mero castigo, punitivo y retributivo, y la concepción bidireccional, de raíz liberal-contractualista, de la sanción, para impulsar a la justicia al diseño de estrategias de reparación dirigidas también a la comunidad o a la sociedad en su conjunto, y que incorporen la dimensión psico-social de los daños y de su reparación. Estas tendencias, por lo demás nada novedosas en las formas de impartición de justicia indígena arraigadas en Ecuador, nos trasladan directamente al ámbito de la llamada justicia restaurativa ${ }^{10} \mathrm{y}$, en casos extremos, incluso y pese las diferencias, al de la justicia transicional ${ }^{11}$.

La LOGJCC resulta acorde con los lineamientos de la Comisión Interamericana de Derechos Humanos que considera que «en modo alguno el acceso a la reparación de las víctimas puede quedar sujeto exclusivamente a la determinación de responsabilidad criminal de los victimarios, ni a la previa ejecución de sus bienes personales, lícitos o ilícitos».

9 Graciela Guilis y Equipo de Salud Mental del Centro de Estudios Legales y Sociales (CELS), «El concepto de reparación simbólica en el contexto jurídico del sistema interamericano: http://www.estadosgerais.org/encontro/IV/ES/trabalhos/Graciela Guilis.pdf

${ }^{10}$ En el ámbito de la justicia restaurativa «las necesidades de las víctimas y el restablecimiento de la paz social son las finalidades básicas que debe tener la respuesta al crimen, por lo que lo importante es reconocer el sufrimiento ocasionado a la víctima, repararle el daño que le fue ocasionado y restaurarla en su dignidad, más que castigar al responsable, a quien debe intentar reincorporarse a la comunidad a fin de restablecer los lazos sociales». Rodrigo Uprimny, Ma Paula Saffon, «Justicia transicional y justicia restaurativa: tensiones y complementariedades»: http://www.idrc.ca/en/ev-84576-201-1-DO TOPIC.html

${ }^{11}$ La noción de Justicia Transicional «surgió con el propósito esencial de equilibrar las exigencias de justicia y de paz en contextos excepcionales de transición de la guerra a la paz o de la tiranía a la democracia caracterizados por la necesidad de enfrentar la violación masiva y sistemática de derechos humanos», y por tener la «nada sencilla tarea de encontrar un punto medio entre los polos de justicia retributiva plena, por un lado, y de impunidad absoluta, por el otro». Ibíd. 
Por su parte, la Corte Interamericana de Derechos Humanos En el caso Masacre Plan de Sánchez (Sentencia de 19 de noviembre de 2004), consideró que «el daño inmaterial puede comprender tanto los sufrimientos y las aflicciones causados a las víctimas directas y a sus allegados, el menoscabo de valores muy significativos para las personas, así como las alteraciones, de carácter no pecuniario, en las condiciones de existencia de la víctima o su familia. No siendo posible asignar al daño inmaterial un preciso equivalente monetario, sólo puede, para los fines de la reparación integral a las víctimas, ser objeto de compensación, y ello de dos maneras. En primer lugar, mediante el pago de una cantidad de dinero o la entrega de bienes o servicios apreciables en dinero, que el Tribunal determine en aplicación razonable del arbitrio judicial y en términos de equidad. Y, en segundo lugar, mediante la realización de actos u obras de alcance o repercusión públicos que tengan efectos como la recuperación de la memoria de las víctimas, el reconocimiento de su dignidad, el consuelo de sus deudos o la transmisión de un mensaje de reprobación oficial a las violaciones de los derechos humanos de que se trata y de compromiso con los esfuerzos tendientes a que no vuelvan a ocurrir» ${ }^{12}$.

La comprensión de la reparación integral debe, además, contar con las previsiones de la Convención de Belém do Pará13 ${ }^{13}$ de la que es parte Ecuador desde 1995, que insta a los Estados a establecer los mecanismos judiciales y administrativos necesarios para asegurar que las mujeres víctimas de violencia — tanto física, psicológica como sexual-, tengan un acceso efectivo a resarcimiento, reparación del daño u otros medios de compensación justos y eficaces.

En cuanto a la reparación de víctimas de otros grupos vulnerables, como los pueblos indígenas y las comunidades afrodescendientes, «el Estado deberá también tomar en cuenta criterios reparatorios diferenciados que incluyan el reconocimiento y respeto a la identidad y a la cultura, el reconocimiento y respeto de sus territorios, y la participación de sus autoridades en todas las decisiones que los afecten» ${ }^{14}$.

12 Corte I.D.H., Caso Masacre Plan de Sánchez. Sentencia de 19 de noviembre de 2004. Serie C No. 116, párr. 80; Véase también Corte I.D.H., Caso De la Cruz Flores. Sentencia de 18 de noviembre de 2004. Serie C No. 115, párr 155; Corte I.D.H., Caso Carpio Nicolle y otros. Sentencia 22 de noviembre. 2004. Serie C No. 117, párr. 117.

13 Convención Interamericana para Prevenir, Sancionar y Erradicar la Violencia contra la Mujer «Convención de Belém do Pará», artículo 7.

${ }^{14}$ Documento de la Comisión Interamericana de Derechos Humanos Presenta dirigido al Gobierno de Colombia donde se recogen los «Lineamientos principales que debe contener una política integral de reparaciones». OEA/Ser/L/V/II.131 Doc. 1 (aprobado por la Comisión el 19 de febrero de 2008):

http://www.cidh.oas.org/pdf\%20files/Lineamientos\%20principales\%20para\%20una\%20política\%20integral\%20de\%20reparaciones.pdf 
En este sentido se reitera la importancia de que el proceso de consulta que se realice incluya a sus autoridades tradicionales ${ }^{15}$.

\subsection{Apelación y selección de casos por la Corte Constitucional}

De acuerdo con el artículo 86.3 de la Constitución, las sentencias de protección de derechos constitucionales de primera instancia podrán ser apeladas ante la corte provincial. Con esta previsión, el modelo de garantía jurisdiccional de los derechos se ubica de modo primario y central en la justicia ordinaria, respondiendo a un doble propósito: por un lado, la mayor proximidad y accesibilidad a los mecanismos de protección de los derechos; por otro, que el conjunto de la justicia ordinaria se constitucionalice, esto es, que configure todas sus funciones y sus prácticas de acuerdo con los valores, principios y reglas contenidas en el nuevo texto constitucional.

Ahora bien, esta constitucionalización deberá ser guiada y supervisada por la Corte Constitucional, algo que en el ámbito de los derechos se articula a través de la posibilidad de revisión de las sentencias firmes de la jurisdicción ordinaria, de conformidad con los artículos 436.6 de la Constitución y 25 de la LOGJCC. En virtud de este último precepto, la Corte Constitucional cuenta con la facultad de seleccionar aquellas sentencias que considere necesario revisar por razón de la gravedad del asunto, la novedad del caso o inexistencia de precedente judicial, la negación por el órgano judicial de instancia de los precedentes fijados por la propia Corte Constitucional, o la relevancia del asunto. La revisión, que en todo caso será discrecional, podrá ser solicitada por la Defensoría del Pueblo o por cualquier jueza o juez, o decidida directamente por la Corte a través de una Sala de Selección. No cabrá recurso alguno respecto de ninguna de las decisiones tomadas por la Corte en el proceso de selección.

15 La especificidad del contenido reparatorio de las resoluciones de la Corte Interamericana puede hallarse, entre otras, en las siguientes resoluciones: Corte I.D.H., Caso Masacre Plan de Sánchez. Sentencia de 19 de noviembre de 2004. Serie C No. 116, párrs. 60 a 111. Corte I.D.H., Caso de la Comunidad Moiwana. Sentencia de 15 de junio de 2005. Serie C No. 124, párrs. 168 a 218. Corte I.D.H., Caso de la Comunidad Mayagna (Sumo) Awas Tingni. Sentencia de 31 de agosto de 2001 Serie C No. 79, párrs. 162 a 172. Corte I.D.H., Caso de la Comunidad Indígena Yakye Axa. Sentencia de 17 de junio de 2005. Serie C No. 125, párrs. 179 a 227. Corte I.D.H., Caso Comunidad Indígena Sawhoyamaxa. Sentencia de 29 de marzo de 2006. Serie C No. 146, párrs. 195 a 247. Corte I.D.H., Caso del Pueblo Saramaka. Sentencia de 28 de noviembre de 2007. Serie C No. 172, párrs. 186 a 202. 
Según la estadística ofrecida por la Corte Constitucional en su portal institucional, entre octubre de 2008 y septiembre de 2011, de un total de 5718 sentencias sobre garantías constitucionales remitidas a la Corte Constitucional, se habían seleccionado y trasladado a la Sala de Revisión un total de 28.

Con tales previsiones, la LOGJCC se emparenta con modelos, como el del Tribunal Constitucional Federal alemán (desde la reforma operada en 1963) o el Tribunal Supremo Federal de los Estados Unidos de América, por citar un modelo de control concentrado y uno de control difuso, que reservan la intervención de la máxima instancia a circunstancias excepcionales que podrán, además, modularse a lo largo del tiempo.

La restricción de las posibilidades de acceso a la Corte Constitucional, dada la centralidad que el texto constitucional pretende dar a los derechos, podría llegar a ser objeto de crítica. Esta crítica puede partir de la desconfianza hacia la capacidad de la jurisdicción ordinaria para responder de manera eficiente a las demandas ciudadanas, especialmente las de quienes tradicionalmente han tenido más dificultades de acceso a la justicia. Podría sostenerse que de poco puede haber servido el esfuerzo constituyente por conformar un «Estado constitucional de derechos», si éstos quedan en manos de una justicia tradicionalmente vista con desconfianza por parte de amplios sectores de la población.

Frente a tal visión, cabe señalar que el esfuerzo constituyente apunta además a un proceso de reformulación de las condiciones de acceso y de funcionamiento de la justicia. Este proceso, precisamente, depende en buena medida de la rapidez e intensidad con que se produzca la constitucionalización del sistema de justicia en su totalidad, para lo que, como ya se apuntó, la atribución a la jurisdicción ordinaria de las funciones de garantía de los derechos constitucionales constituye una pieza fundamental.

Por otra parte, existen experiencias, como la de la justicia constitucional en España, que han transitado de un modelo más abierto de acceso a fórmulas de mayor restricción. Como es sabido, tras 25 años de actividad del Tribunal Constitucional, se aprobó la Ley Orgánica 6/2007, por la que, entre otros aspectos, se reforman las condiciones de admisión del recurso de amparo frente a vulneraciones de derechos constitucionales. La principal razón esgrimida fue la inasumible cantidad de recursos acumulados (hasta 8.000 pendientes del trámite de admisión en el momento de la reforma), algo que afectaba a las posibilidades de tratar eficientemente tanto el amparo como el resto de acciones constitucionales $^{16}$. Tras la reforma, los recursos de amparo que llegan al Tribunal son objeto de

${ }^{16}$ Existen a día de hoy bastantes aportaciones doctrinales sobre la reforma. Entre otras, se puede consultar Marc Carrillo, «La objetivación del recurso de amparo: una necesidad ineludible», Re- 
una decisión de admisión a trámite en la que se valora si el contenido del recurso justifica una decisión sobre el fondo en razón de su especial trascendencia constitucional ${ }^{17}$.

Puede ser de utilidad para nuestra reflexión añadir algo más sobre las razones de la llamada objetivización del amparo en España. En su labor de máximo garante de la eficacia de los derechos fundamentales, el Tribunal Constitucional había llegado a erigirse como un órgano de súper casación de una parte importante de las resoluciones de la jurisdicción ordinaria. En este sentido, Roberto Romboli subraya cómo ese papel le había llevado, además, a sacrificar las funciones que «habría que considerar como más características de los Jueces constitucionales: el control de las leyes y la resolución de los conflictos; funciones éstas que están bajo la exclusiva competencia de los Jueces constitucionales y son, como se ha señalado, el fundamento mismo de su existencia, mientras que, y al contrario, la tutela de los derechos fundamentales está garantizada también (o «in primis») por los jueces ordinarios, e incluso bastantes ordenamientos (entre los que se encuentra el italiano) no conocen la institución del amparo o del recurso directo e individual ${ }^{18}$.

De todas formas, siendo la intención de la reforma, como se señala en su exposición de motivos, otorgar a los tribunales ordinarios «el papel de primeros garantes de los derechos fundamentales», no habría que descartar reformas orientadas a reforzar el procedimiento preferente y sumario de protección de derechos fundamentales en manos de la jurisdicción ordinaria. En este sentido se ha pronunciado una parte importante de la doctrina ${ }^{19}$.

vista Vasca de Administración Pública, núm. 81, pp. 87-109. Jaime Suau Morey «Reforma de la Ley Orgánica del Tribunal Constitucional», Jueces para la democracia, núm. 61, pp. 117-130. Manuel Aragón Reyes, «La reforma de la Ley Orgánica del Tribunal Constitucional», Revista Española de Derecho Constitucional, núm. 85, pp. 11-43. Ana Espinoza Díaz, «El recurso de amparo: problemas antes, y después, de la reforma», Publicación electrónica InDret, Revista para el análisis del derecho, visitada en septiembre de 2011: http://www.indret.com/pdf/722_es.pdf

17 Concretamente, tras la reforma de 2007, el artículo 50.1 de la Ley Orgánica del Tribunal Constitucional (LOTC 2/1979, de 3 de octubre) establece como requisito para la admisión a trámite: «b) Que el contenido del recurso justifique una decisión sobre el fondo por parte del Tribunal Constitucional en razón de su especial trascendencia constitucional, que se apreciará atendiendo a su importancia para la interpretación de la Constitución, para su aplicación o para su general eficacia, y para la determinación del contenido y alcance de los derechos fundamentales».

18 Roberto Romboli, «La reforma del recurso de amparo ante el Tribunal Constitucional en España y la introducción de un recurso individual y directo en Italia»: http://www.ugr.es/ redce/REDCE11/articulos/11RobertoRomboli.htm

${ }^{19}$ Carrasco Durán señala que «la dificultad, sin embargo, surge al tratar de idear una vía alternativa que pudiera dar cauce a las demandas de amparo de los derechos fundamentales que ya no van a tener cabida en el recurso de amparo. En todo caso, sería necesario acudir a soluciones imaginativas. 


\section{LAS ACCIONES DE PROTECCIÓN DE LOS DERECHOS CONSTITUCIONALES: APORTACIONES MÁS RELEVANTES DE LA LOGJCC}

\subsection{Medidas Cautelares}

La Constitución, en su artículo 87, se limita a establecer que «se podrán ordenar medidas cautelares conjunta o independientemente de las acciones constitucionales de protección de derechos, con el objeto de evitar o hacer cesar la violación o amenaza de violación de un derecho». Por tanto, la apuesta por un procedimiento detallado, y diferenciado en un capítulo propio, para la adopción de medidas cautelares debe considerarse como una de las principales aportaciones de la LOGJCC en la materia. De nuevo en esta materia está presente una síntesis de la evolución del tratamiento que el sistema interamericano ha efectuado por medio de las medidas cautelares dictadas por la Comisión y las medidas provisionales emanadas de la Corte ${ }^{20}$.

La LOGJCC recoge de manera especial el sentido no formalista de la protección de los derechos, que en sede de medidas cautelares es si cabe más necesario, al señalar su carácter «sencillo, rápido y eficaz en todas sus fases» para luego obligar a la jueza o juez a «buscar los medios más sencillos que estén a su alcance para proteger el derecho» (artículo 31). Otro de los elementos centrales es las medidas deberán ser adoptadas si la jueza o juez «verifica por la sola descripción de los hechos que se reúnen los requisitos previstos en esta ley» sin exigirse pruebas (artículo 33).

Rompe, sin embargo, la dimensión extensiva y garantista de las medidas cautelares la restricción de su ámbito contenida en el párrafo tercero del artículo

Podría pensarse en la posibilidad de crear un proceso extraordinario de amparo de los derechos fundamentales mencionados en el artículo 53.2 de la Constitución una vez agotada la vía judicial ordinaria cuyo conocimiento podría quedar confiado a Salas de Derechos Fundamentales de los Tribunales Superiores de Justicia, en relación con los procesos cuya última instancia termine ante órganos judiciales cuya competencia se extienda a un territorio menor del de una Comunidad Autónoma, y a una Sala de Derechos Fundamentales del Tribunal Supremo, en relación con los procesos cuya última instancia termine ante los Tribunales Superiores de Justicia o ante órganos judiciales de ámbito territorial extendido a la totalidad del Estado. Podría pensarse también en articular un mecanismo mediante el que el Tribunal Constitucional tuviera que remitir los recursos de amparo inadmitidos por su falta de interés constitucional a dichas Salas de Derechos Fundamentales», Manuel Carrasco Durán, «Amparo judicial: presente y futuro», Revista de Derecho Político, núm. 68, 2007, pp. 145-182, p. 181.

${ }^{20}$ Un análisis sobre la cuestión puede hallarse en Ernesto Rey Cantor y Ángela Rey Anaya, Medidas provisionales y medidas cautelares en el sistema interamericano de derechos bumanos, disponible en formato electrónico: http://www.bibliojuridica.org/libros/libro.htm?l=2047 
27 , en virtud del cual éstas «no procederán cuando existan medidas cautelares en las vías administrativas u ordinarias, cuando se trate de órdenes judiciales o cuando se interpongan en la acción extraordinaria de protección». Sin duda, se trata de una limitación de difícil justificación en el marco de una regulación cuyo sentido es otro.

Por lo que respecta al primer inciso, en tanto que excepción al principio general, deberá interpretarse en términos restrictivos, esto es, solo cuando existan en otras vías, en el sentido de que se hayan ya implementado, medidas cautelares que resulten, además, adecuadas y eficaces, la jueza o juez deberá rechazar la adopción de ulteriores cautelares.

Respecto del veto a adoptar medidas cautelares frente a órdenes judiciales o en el marco de las acciones extraordinarias de protección de derechos, se podría entender que la idea de fondo sea la de evitar que las medidas cautelares sean utilizadas como mecanismos para generar dilaciones o retrasos en la impartición de justicia. Ahora bien, como la propia LOGJCC hace, por ejemplo en la regulación de la acción extraordinaria de protección de los derechos, existen herramientas que permiten acotar dicho abuso de la institución, como por ejemplo la imposición de sanciones ante un uso irrazonable o temerario.

Si se quiere, las limitaciones podrían tratar de justificarse sosteniendo que la LOGJCC estaría pensada para ser aplicada en un escenario en el que el conjunto de reformas institucionales de desarrollo de la nueva Constitución habría generado un contexto en el que el sistema de impartición de justicia, en sí mismo, contaría con una batería suficiente de protección de los derechos y, en consecuencia, no sería necesario una garantía cautelar de orden constitucional suplementaria. Ahora bien, más allá de que tal hipótesis pueda ser cuestionada en sus realizaciones concretas, lo cierto es que ningún poder, tampoco el judicial, puede pensarse fuera de la lógica que lo sitúa, en tanto que poder, como potencial amenaza de los derechos. Ese es el presupuesto del constitucionalismo y su cuestionamiento afecta a su propia esencia.

\subsection{Acción de Protección}

La acción de protección, según el artículo 88 del texto constitucional ecuatoriano, tiene por objeto «el amparo directo y eficaz de los derechos reconocidos en la Constitución, y podrá interponerse cuando exista una vulneración de derechos constitucionales, por actos u omisiones de cualquier autoridad pública no judicial; contra políticas públicas cuando supongan la privación del goce o ejercicio de los derechos constitucionales; y cuando la violación proceda de una persona particu- 
lar, si la violación del derecho provoca daño grave, si presta servicios públicos impropios, si actúa por delegación o concesión, o si la persona afectada se encuentra en estado de subordinación, indefensión o discriminación».

El principal motivo de debate es la caracterización que la LOGJCC hace de esta acción como mecanismo subsidiario o residual. Sin duda, del redactado del artículo 88 constitucional se deriva que la voluntad del constituyente era asegurar un mecanismo «directo y eficaz» de protección de los derechos, de manera que sólo podría interpretarse su carácter subsidiario frente a otros mecanismos constitucionalmente previstos, específicos para la garantía de ciertos derechos o ámbitos de protección (hábeas corpus, acceso a la información pública, hábeas data, acción de incumplimiento ${ }^{21}$, acción extraordinaria de protección y acción extraordinaria de protección frente a decisiones de la justicia indígena).

Pero la LOGJCC añade como requisito para su admisión (artículo 40.3) «que no exista otro mecanismo de defensa judicial adecuado y eficaz para proteger el derecho violado». Frente a tal previsión, además de la posibilidad de impugnar su constitucionalidad, cabe trazar dos posibles interpretaciones conducentes a hacer compatible dicha exigencia con el tenor de la previsión constitucional.

a) Una primera interpretación señalaría que el requisito exigido por el artículo 40.3 para la admisión de la acción de protección, se refiere al resto de acciones previstas constitucionalmente, a las que habría que añadir otra exclusión: en virtud del artículo 42.7 de la misma ley no podrá utilizarse la acción de protección cuando el acto u omisión origen de la vulneración emane del Consejo Nacional Electoral y pueda ser impugnado ante el Tribunal Contencioso Electoral.

b) Una segunda interpretación apuntaría a exigir que los órganos judiciales admitan toda acción de protección que se sustancie ante ellos a no ser que exista otra acción, no sólo constitucional, sino también de tipo legal, aunque en circunstancias especiales: cuando por su especificidad y por las características propias del procedimiento regulado aseguren una mejor protección, en términos de celeridad, inmediatez y accesibilidad, a la persona afectada por la presunta vulneración del derecho (así por ejemplo, las acciones de tipo penal, o las de tipo civil que tengan como objeto la protección de derechos). De este modo, quedarían fuera de la acción de protección las reclamaciones vinculadas exclusivamente a derechos patrimoniales y de origen privado contractual ${ }^{22}$. Ratificaría esta inter-

21 Se produce una contradicción en este punto que más adelante, al abordar el comentario de la acción por incumplimiento, abordaremos.

22 Merece la pena acudir a la distinción esencial que realiza Ferrajoli entre derechos patrimoniales y derechos fundamentales. Los primeros pertenecen a cada sujeto de manera individual y 
pretación el hecho de que el ya mencionado artículo 42.7 prevea un caso que, claramente, encaja con el supuesto planteado: la existencia de una acción específica ante el Tribunal Contencioso Electoral frente a acciones u omisiones del Consejo Nacional Electoral.

Existe además un argumento serio para entender las razones que llevan a la reducción del ámbito de la acción de protección. Como nos enseña el caso de la acción de tutela colombiana establecida por la Constitución de 1991, este tipo de amparo constitucional está pensado para hacer frente inmediata y eficaz a vulneraciones, actuales o inminentes, de derechos mediante respuestas que, en buena medida, pueden resultar coincidentes con las medidas cautelares. Siendo éstas, como hemos visto, reguladas por la LOGJCC como una acción sustantiva, autónoma, se podría decir que el sistema ecuatoriano ya cuenta con un mecanismo rápido y efectivo de respuesta ante las vulneraciones de derechos y que de ser necesaria una mayor clarificación del alcance de la vulneración, de las responsabilidades y de las medidas de reparación integral, caben otras vías judiciales y, subsidiariamente, el propio amparo que ofrece la acción de protección.

Más allá de las posibilidades interpretativas señaladas, hay que tener en cuenta que, además, de la redacción de la LOGJCC se puede generar alguna duda respecto del sentido del carácter subsidiario o residual de la acción de protección. Una opción sería entenderla como exigencia de haber agotado las vías judiciales previas, en todo caso $^{23}$; otra posibilidad, en cambio, es la ya señalada de su carácter residual, que permitiría que sólo pudiera interponerse cuando no existan otras vías, pero no porque éstas se hubieran agotado de manera previa, sino sencillamente porque el ordenamiento no prevea acciones específicas adecuadas y eficaces.

Por otro lado, la resolución de la acción de protección debería entenderse de cognición limitada y que sólo podría tener como objeto declarar la restitución del derecho vulnerado pero no entraría a determinar cuestiones que puedan tener que ver con la responsabilidad penal, administrativa, civil, etc., que deberá

su ejercicio por parte del titular excluye al resto. El autor italiano afirma que estos derechos tienen una naturaleza distinta al resto de derechos pues mientras los derechos fundamentales son la base de la igualdad, por su carácter generalizable, los derechos patrimoniales están en la base de las dinámicas de desigualdad. Prueba de ello es que solo los derechos patrimoniales son disponibles, alienables y negociables, mientras que los derechos fundamentales son indisponibles y no admiten renuncia ni negociación alguna por su titular. Vid. Luigi Ferrajoli, Derechos y garantías. La ley del más débil, Trotta, Madrid, 2001.

${ }_{23}$ Este es el caso, por ejemplo, del modelo español de recurso de amparo, que debe presentarse ante el Tribunal Constitucional pero solamente una vez agotada la vía judicial previa (artículos 43 y 44 de la Ley Orgánica del Tribunal Constitucional, 1979). 
solventare por las vías jurisdiccionales ordinarias previstas al efecto. Estas y otras cuestiones merecen un análisis mucho más hondo del que estas páginas pueden llegar a ofrecer.

Una última cuestión que puede resultar de interés es la referida a la legitimación activa de la Defensoría del Pueblo en las acciones de protección. Aunque tradicionalmente se trata de una institución que ha tenido como función el control de la actividad de los poderes públicos, nada impediría, sino todo lo contrario, que presente una acción de protección para proteger a un particular frente a la acción de otro particular, cuando, como señala el artículo 88 constitucional, si la violación del derecho provoca daño grave o si la persona afectada se encuentra en estado de subordinación, indefensión o discriminación. Se trata de una muestra más de la apuesta por un constitucionalismo que debe proporcionar mecanismos para la limitación y control del poder, de todo tipo de poder, público y privado. Desde la perspectiva de los derechos, hablamos de su comprensión como herramientas contra mayoritarias y emancipadoras, especialmente referidas a la protección de los sujetos más vulnerables respecto de los sujetos con más poder ${ }^{24}$.

\subsection{Acción de bábeas corpus}

De la acción de hábeas corpus merece la pena subrayar que la regulación que hace tanto la Constitución (artículo 89) como la LOGJCC constituye un ejemplo de garantismo en materia de derechos. Son muestra de ello: la incorporación de un listado, abierto, de derechos especialmente amenazados en condiciones de privación de libertad (artículo 43 de la LOGJCC), con la determinación del plazo máximo que puede durar una situación de prisión preventiva (artículo 77.9 constitucional y 43.8 LOGJCC); la posibilidad de acudir a cualquier jueza o juez del lugar donde se presuma que la persona está privada de libertad (artículo 44.1); la celeridad de la audiencia (en un plazo máximo de veinticuatro horas); la presunción del carácter ilegítimo o arbitrario de la privación de libertad cuando las persona no fuese presentada a la audiencia, cuando no se exhiba la orden de privación de libertad o ésta no cumpla los requisitos legales o constitucionales, entre otros supuestos (artículo 45); la previsión específica de los supuestos de desapariciones forzadas: bastará la existencia de indicios de participación de servidores públicos para que la juez o juez deban convocar en audiencia al máximo representante de la Policía Nacional o del ministerio competente (artículo 46).

${ }^{24}$ En este sentido, merece acudir, de nuevo, a la obra de Luigi Ferrajoli, Derechos y garantías. La ley del más débil, ob. cit. 


\subsection{Acción por incumplimiento}

La regulación de la acción por incumplimiento, dada la amplitud del objeto y de los requisitos para su planteamiento, es fuente de confusión. La Constitución, en su artículo 93, se refiere en términos muy abiertos a su objeto, que es el de «garantizar la aplicación de las normas que integran el sistema jurídico, así como el cumplimiento de sentencias o informes de organismos internacionales de derechos humanos». La única restricción que se añade es que la norma o decisión cuyo cumplimiento se persigue deberá contener «una obligación de hacer o no hacer clara, expresa y exigible».

La LOGJCC incorpora dos elementos con el objeto de limitar su ámbito de aplicación. Por un lado, el trámite de la reclamación previa del cumplimiento de la obligación (artículo 54). Por otro lado, una serie de causas de inadmisión que determinan su carácter residual o subsidiario: no procederá la acción cuando el objeto sea la protección de derechos que puedan ser garantizados mediante otra garantía jurisdiccional; cuando el incumplimiento se refiera a mandatos constitucionales (para ello se prevé el control constitucional de las omisiones normativas); cuando exista otro mecanismo judicial para lograr el cumplimiento, salvo en los casos en que la acción por incumplimiento prevenga mejor que no se deriven perjuicios graves e inminentes.

Si se quiere, el hecho de que la acción deba interponerse directamente ante la Corte Constitucional podría considerarse como un tercer elemento propio de la lógica de la limitación del ámbito de su aplicación, pues determina una menor proximidad y, necesariamente, impone una lógica más excepcional, más residual respecto del resto de acciones jurisdiccionales.

Por último, se puede advertir un problema en la regulación de la subsidiariedad: la LOGJCC, como ya se ha señalado, entiende que la acción por incumplimiento no procede si la acción es interpuesta para proteger derechos que puedan ser garantizados mediante otra garantía jurisdiccional (artículo 56.1). Según vimos, la acción de protección resulta subsidiaria del resto de acciones constitucionales, cuando menos, y entre ellas la acción de incumplimiento. De esta forma se genera una recíproca subsidiaridad entre ambas acciones. Frente a tal antinomia, debe defenderse que la acción de protección, como parte del grupo de acciones de garantía de los derechos, deberá utilizarse cuando de la protección de un derecho se trate y sólo si no es así se podrá entonces acudir a la acción de incumplimiento. Seguramente sería mejor no tratar este tema en términos de subsidiariedad porque en realidad lo que se produce es una distinción por razones materiales, en función de si lo que debe tratarse es una cuestión de derechos o no. 


\subsection{Acciones extraordinarias de protección}

La posibilidad de reclamar frente a las vulneraciones de derechos acaecidas en el marco de procesos judiciales estaba expresamente vetada por la Constitución de 1998. Por tanto, nos hallamos ante una importante novedad que merece ser comentada.

En el marco de la protección constitucional de los derechos, más allá del control del poder ejecutivo y de la administración, la posibilidad de supervisar la actividad judicial ha devenido una cuestión central. El hecho de que la realización de los derechos constituya la razón de ser de la organización política, justifica que aquéllos que, en primer término, están llamados a verificar su cumplimiento, no puedan quedar al margen de un ulterior control. Este control debe tener la capacidad de filtrar la actividad judicial por el tamiz de los derechos constitucionales, dejando al margen la revisión de cuestiones de mera legalidad y, con más razón, de oportunidad en el marco de la capacidad decisoria, a menudo apoyada en un margen de discrecionalidad, de las juezas y los jueces.

Habitualmente, el estamento judicial ha venido a representar, en términos generales, un sector más conservador, más reacio a los cambios, por razones sociopolíticas y por una esencia conservadora que ha impregnado la práctica jurídica. En ocasiones, profundas transformaciones constitucionales se han tenido que enfrentar a las inercias, las dudas, las objeciones de los operadores judiciales y, en tales contextos, de los que el caso español resulta paradigmático, ha sido necesario un insistente control constitucional de su actividad como acompañamiento necesario de un proceso de transición que permita una cambio de mentalidad, de cultura, una verdadera constitucionalización de su actividad. Pues bien, esas son las motivaciones que explican la centralidad en el nuevo orden de la acción extraordinaria de protección, pues, como señala la LOGJCC en sus considerandos, uno de sus principales propósitos es la constitucionalización de la justicia, que deberá ser liderada por la Corte Constitucional.

En este contexto, pueden llegar a encajar de modo justificado las limitaciones que la LOGJCC prevé con el objeto de evitar que la acción dé paso a una nueva instancia de revisión judicial, esto es, las que se refieren a que la acción no pueda plantearse cuando el fundamento de la misma se reduce a la consideración de lo injusto o equivocado de la resolución (artículo 62.3), en la falta de aplicación de una norma (artículo 62.4), o en la valoración de una prueba (artículo 62.5).

Sin embargo son más cuestionables aquéllas que introducen otro tipo de restricciones, concretamente dos: no es posible interponer la acción frente a decisiones del Tribunal Contencioso Electoral durante procesos electorales (artículo 62.7); se permite que la Corte Constitucional, que es la instancia competente, rechace el conocimiento de la acción cuando considere que no permita «solventar 
una violación grave de derechos, establecer precedentes judiciales, corregir la inobservancia de precedentes establecidos por la Corte Constitucional»o «sentenciar sobre asuntos de relevancia y trascendencia constitucional» (artículo 62.8).

En ambos casos la explicación puede hallarse en la voluntad de impedir que la acción sirva para interferir o retardar la justicia, algo que se hace especialmente necesario en el ámbito de los procesos electorales. En el ámbito electoral, la medida adoptada es la exclusión absoluta de la revisión de las decisiones del Tribunal Contencioso Electoral y por ello puede afirmarse que lo atendible del objetivo no justifica la desmesura de los medios. Otras opciones hubieran sido más ponderadas, como el establecimiento de un plazo más corto para su resolución, de causas limitativas, o de sanciones disuasorias frente a estrategias dilatorias. Sucede que tampoco es posible la acción de protección, pues el artículo 42.6 rechaza que sean revisables en protección las providencias judiciales, de manera que sólo cabría buscar la garantía que pueda ofrecer la acción por incumplimiento, siempre y cuando existiera una «obligación de hacer o no hacer, clara, expresa y exigible» (artículo 52 de la LOGJCC). En este sentido, además, no parece que existiendo la vía de la acción por incumplimiento ante la Corte Constitucional, existan muchos motivos concluyentes para impedir de raíz que pueda interponerse la acción extraordinaria de protección, cuyo objeto es el control de las actuaciones judiciales.

Con referencia a la incorporación de criterios de admisibilidad, esto es, una objetivización parecida a la que ya analizamos en sede de la acción de protección, podríamos pensar que el legislador ha entendido que el proceso de constitucionalización de la justicia en Ecuador va a vivir distintos momentos y que es preferible que la Corte Constitucional pueda tener un margen para entrar a controlar la actuación judicial con mayor o menor asiduidad en función de las circunstancias, evitando que, por regla, sea vista como una especie de súper casación, una revisión última frente toda actuación judicial. Es cierto que la propia LOGJCC ya establece algunas precauciones frente a esta posibilidad, como el hecho de que en ningún caso la admisión de la acción suspenda los efectos de la resolución impugnada (artículo 62, penúltimo párrafo), que no quepa la solicitud de medidas cautelares (artículo 27 tercer párrafo), o la previsión de sanciones para las abogadas o abogados en casos de ausencia total de fundamento (artículo 64). No obstante, de acuerdo con los argumentos esgrimidos, la restricción impuesta por el artículo 62.8 podría defenderse siempre y cuando, al mismo tiempo, se exija que la Corte Constitucional no utilice dicha cláusula para desahogarse de causas sino, más bien, como válvula que, además, permitiría tener un indicador sobre la vitalidad o salud constitucional de la administración de justicia. 


\subsection{Acción extraordinaria de protección contra decisiones de la justicia indígena}

La incorporación de una acción especial, extraordinaria, contra decisiones de la justicia indígena, cierra el apartado de acciones de protección de derechos constitucionales. Esta acción no se encuentra explícitamente prevista por la Constitución, que se limita a señalar que «El Estado garantizará que las decisiones de la jurisdicción indígena sean respetadas por las instituciones y autoridades públicas. Dichas decisiones estarán sujetas al control de constitucionalidad» (artículo 171, segundo inciso).

Pues bien, la LOGJCC ha optado por regular ese control de constitucionalidad en forma de una específica acción de defensa de los derechos. Como trataremos de desarrollar a continuación, nos hallamos ante uno de los espacios donde de manera más diáfana se puede advertir la tensión que genera la incorporación de derechos de dimensión colectiva en un marco normativo constitucional que, en términos generales, no ha dejado atrás la concepción individual de los derechos y de la conformación misma del espacio social y político. Veamos en qué se manifiesta esta tensión.

En primer lugar, el ámbito de la acción extraordinaria de protección (artículo 65 de la LOGJCC) reconoce el derecho del individuo sujeto a una autoridad indígena a demandar la protección de sus derechos frente a las decisiones de dicha autoridad. Hasta ahí se puede decir que lo que hace la LOGJCC es asegurar la igualdad entre todas las personas y que ninguna pueda quedar al margen de la vigencia de los derechos constitucionales. Ahora bien, se advierte enseguida una diferencia: solo en este caso la jurisdicción competente es de manera directa la Corte Constitucional. ¿Por qué? Porque se entiende que existe una distinción esencial: la jurisdicción ordinaria, por mucho que esté investida por la LOGJCC de dimensión constitucional, responde, representa, al conjunto de la población no indígena de manera que resulta necesario evitar que sea esta jurisdicción la que conozca de las acciones de defensa de los derechos frente a decisiones de autoridades indígenas.

Ahora bien, ¿resulta la Corte Constitucional un ámbito de protección genuinamente intercultural o plurinacional (por utilizar caracteres que definen al Estado, según el artículo 1 constitucional)? Pues bien, de manera apresurada, podemos afirmar que no parece que el modo en que está regulada la conformación de sus miembros, según la cual se les exige, entre otros requisitos, tener título de tercer nivel en Derecho legalmente reconocido en el país (Art. 433.2 de la Constitución), busque asegurar tal carácter.

Consciente de ello, la LOGJCC ha optado por incorporar una serie de elementos dirigidos a poner en relación los distintos intereses y derechos en juego, 
entre los que se encuentran los derechos (constitucionales) de las comunidades, pueblos y nacionalidades indígenas a «mantener, desarrollar y fortalecer libremente su identidad, sentido de pertenencia, tradiciones ancestrales y formas de organización social» (artículo 57.1 de la Constitución), a «conservar y desarrollar sus propias formas de convivencia y organización social, y de generación y ejercicio de la autoridad, en sus territorios legalmente reconocidos y tierras comunitarias de posesión ancestral» (artículo 57.9) y, específicamente, a «crear, desarrollar, aplicar y practicar su derecho propio o consuetudinario, que no podrá vulnerar derechos constitucionales, en particular de las mujeres, niñas, niños y adolescentes» (artículo 57.10).

En efecto, en su artículo 66, de manera algo desordenada pues se mezclan principios, criterios de interpretación y reglas de procedimiento, la LOGJCC recoge una serie de elementos que deben orientar a la Corte Constitucional hacia resoluciones que, como señala el mencionado artículo en su numeral 12, puedan ser «moduladas», para «armonizar los derechos constitucionalmente garantizados y los derechos propios de la comunidad, pueblo o nacionalidad». Sucede que estos últimos derechos son, con igual jerarquía, «derechos constitucionalmente garantizados». Este «lapsus», si se quiere ver así, se puede tomar como elemento indicador de que, a fin de cuentas, la LOGJCC parece no poder salirse del esquema, ya clásico, de una inamovible contradicción entre derechos individuales y derechos colectivos. Prueba de ello sería, además, la insistencia que se hace respecto de que la protección ofrecida es frente a vulneraciones de derechos y acciones de discriminación a la mujer «por el hecho de ser mujer» (artículo 65). Esta reiteración, pues dicha discriminación es en sí misma una vulneración de derechos constitucionales, adopta la forma de sospecha genérica y se subraya al preverse que la Corte deberá «impedir que en sentencias de justicia indígena se alegue la costumbre, la interculturalidad o el pluralismo jurídico para violar los derechos humanos o de participación de las mujeres» (artículo 66.14) ${ }^{25}$.

Dicho lo anterior, es posible, y necesario, destacar algunas de las previsiones que la LOGJCC efectúa para tratar de buscar un cierto equilibrio. En primer lugar, destaca la referencia a la necesidad de asegurar un procedimiento que garantice «la comprensión intercultural de los hechos y una interpretación intercultural de las normas aplicables a fin de evitar una interpretación etnocéntrica y monocultural» (artículo 66.1).

${ }^{25}$ Debe señalarse, no obstante, que ese celo respecto de la igualdad entre mujeres y hombres deriva de la propia Constitución, que al recoger los derechos de los pueblos indígenas también insiste en que «el Estado garantizará la aplicación de estos derechos colectivos sin discriminación alguna, en condiciones de igualdad y equidad entre mujeres y hombres» (artículo 57 último inciso). 
En segundo lugar, es muy relevante la mención a la autonomía de las nacionalidades, pueblos y comunidades, referencia cuidadosamente excluida del texto constitucional (sólo se incorpora respecto de los pueblos en aislamiento voluntario). Quizás por la evidencia de la voluntad constituyente de no mencionar la autonomía, la LOGJCC señala que «no obstante el reconocimiento máximo de autonomía, tiene los límites establecidos por la Constitución vigente, los instrumentos internacionales de derechos de los pueblos indígenas y esta ley». Podría advertirse, de todas formas, una doble intención en la mención al límite que los instrumentos internacionales imponen a la autonomía indígena, pues en realidad al referirse a ellos la LOGJCC recuerda la centralidad que el derecho a la libre determinación de los pueblos indígenas adquiere en tales instrumentos ${ }^{26}$.

Resulta necesario insistir, en este terreno de potencial contradicción entre derechos, en que más que establecer algunos criterios que impidan el total sacrificio de unos (los derechos colectivos) en favor de otros (los individuales), quizás hubiera sido mejor referirse en términos generales a los métodos y reglas de interpretación constitucional que la LOGJCC establece de modo general en su artículo 3, y concretamente a la ponderación y al principio de proporcionalidad, que resultan de enorme utilidad para cualquier colisión entre derechos, sean del tipo que sean.

En definitiva, podemos ver en la regulación de la acción extraordinaria de protección contra decisiones de la justicia indígena una muestra de que aunque la Constitución ecuatoriana de 2008 apueste por un amplio reconocimiento de derechos y de sujetos, junto con ambiciosos objetivos de transformación social, no parece que apunte tan nítidamente a un cuestionamiento del patrón monocultural de la institucionalidad y del ordenamiento jurídico. La interculturalidad, que forma parte de la definición de la forma del Estado realizada constitucionalmente (artículo 1), conlleva que no baste el reconocimiento de la existencia de múltiples culturas (multiculturalidad), sino que los distintos poderes de dimensión pública queden obligados a garantizar unas condiciones equitativas de participación en el diálogo entre dichas culturas (interculturalidad). Sin la promoción de dichas condiciones, que apuntan también a la construcción de identidades inclusivas, se abona el terreno de la dominación de la cultura o culturas hegemónicas sobre las minoritarias, por mucho que estén reconocidas constitucionalmente. Pese a los avances contenidos en la Constitución ecuatoriana de 2008 y, en el ámbito que le concierne, en la LOGJJC, podemos concluir

26 Concretamente, el Convenio núm. 169 de la OIT (1989), del que es parte Ecuador, y la Declaración sobre Derechos de los Pueblos Indígenas de Naciones Unidas (2007). 
señalando que el patrón occidental sigue dejándose notar como paradigma dominante ${ }^{27}$.

Title

NO GUARANTEES NO RIGHTS. WITHOUT RIGHTS THERE IS NO CONSTITUTION. NOTES ON THE LEGAL PROTECTION OF RIGHTS IN ECUADOR

\section{Summary:}

1. Introduction. 2. Judicial guarantees of constitutional rights: general issues. 2.1. General principles of procedure. 2.2. Integral repair. 2.3. Appeal and selection of cases by the Constitutional Court. 3. The actions to protect the constitutional rights of the most important contributions of the LOGJCC. 3.1. Precautionary Measures. 3.2. Actions of Protection. 3.3. Action of habeas corpus. 3.4. Actions for noncompliance. 3.5. Shares outstanding protection. 3.6. Action decisions extraordinary protection of indigenous justice.

\section{Resumen:}

El presente texto centra su análisis en las garantías jurisdiccionales de los derechos recogidos por la vigente Constitución ecuatoriana, de acuerdo con el desarrollo que de las mismas ha realizado la Ley Orgánica de Garantías Jurisdiccionales y Control Constitucional, de 21 de septiembre de 2009. Para cubrir tal objetivo, se parte de una breve introducción sobre el marco constitucional en el que dichas garantías encuentran asiento, desarrollando la definición contenida en su primer artículo según la cual el Estado ecuatoriano es un «Estado constitucional de derechos». A continuación se analiza el conjunto de principios generales del procedimiento comunes a los distintos mecanismos de protección de los derechos constitucionales, como son la oralidad, la gratuidad, la inmediación, la celeridad y economía procesal, y el anti-formalismo. Por último, se abordan una por una las distintas vías de protección de los derechos recogidas por la Constitución de 2008, de acuerdo con las aportaciones más

27 Una reflexión sobre el alcance de las transformaciones constitucionales en el ámbito del reconocimiento de los derechos de los pueblos indígenas y su relación con el Estado, puede verse en Aparicio Wilhelmi, M, «Pueblos indígenas y constitucionalismo: de la igualdad multicultural al diálogo entre iguales», en Aparicio Wilhelmi, M (ed.), Los derechos de los pueblos indígenas a los recursos naturales y al territorio. Conflictos y desafíos en América Latina, Icaria, Barcelona, 2011. 
relevantes de la Ley Orgánica de Garantías Jurisdiccionales y Control Constitucional.

\section{Abstract:}

This paper focuses its analysis on the rights' judicial guarantees set by the current Constitution of Ecuador, according to the development made by the Ley Orgánica de Garantías Jurisdiccionales y Control Constitucional (September 21th, 2009). To reach this goal, a brief introduction discusses the constitutional framework in which such guarantees are seat, and developed the definition settled in the first constitutional article under which the State is a Constitutional State of rights (Estado constitucional de derechos). Then we analyze the set of general procedure principles to different mechanisms of protection of constitutional rights, such as oral, cost-free, immediacy, speed and procedural economy, and antiformalism. Finally, we analyze one by one the different instruments for the protection of rights collected by the 2008 Constitution, according to the most important contributions of the Ley Orgánica de Garantías Jurisdiccionales y Control Constitucional.

\section{Palabras clave:}

Derecho constitucional, constitucionalismo latinoamericano, derechos fundamentales, garantías constitucionales

\section{Key words:}

Constitutional Law, Latin-American Constitutionalism, Fundamental Rights, Constitutional Guarantees 